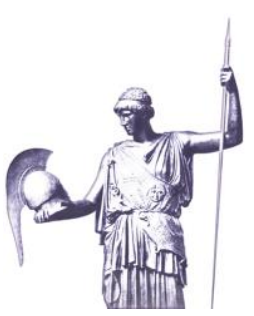

Рецензированная статья
Connections: The Quarterly Journal

ISSN 1812-1098, e-ISSN 1812-2973

Насиров, Искандаров, Садиев, Connections QJ 16, № 3 (2017): 53-63 https://doi.org/10.11610/Connections.rus.16.3.03

\title{
Южный Кавказ: поле игры между НАТО и Россией?
}

\section{Эльман Насиров, ${ }^{a}$ Хаял Искандаров ${ }^{b}$ и Сади Садиев ${ }^{b}$}

a Институт политических исследований Академии публичной администрации при Президенте Азербайджана

b Военная академия вооруженных сил, Республика Азербайджан

Резюме: В этой статье делается анализ вызовов и перспектив сотрудничества между странами Южного Кавказа и НАТО. Рассматриваются геоэкономическое, геополитическое и геостратегическое значение этого региона как для НАТО, так и для Организации Договора о Коллективной Обороне (в частности, для России), и их реципрокные ожидания о развитии дальнейшего сотрудничества с Альянсом. Анализируется положение дел в регионе Южного Кавказа и возможные последствия российского влияния на создание более близких отношений с НАТО. Показана среда безопасности после российско-грузинской войны и ее отражение на сотрудничество Южного Кавказа и НАТО. Выдвигается на первый план то, как заинтересованность НАТО В этом регионе будет содействовать европейской системе безопасности в обозримом будущем. Рассматриваются причины нежелания Альянса активно ангажировать себя делами данного региона. Представлены рекомендации, направленные на уравновешивание российского военного присутствия в регионе без антагонистического противопоставления действующему правительству в Москве и на устранение так называемых "замороженных конфликтов» для обеспечения безопасности и процветания Южного Кавказа в целом.

Ключевые слова: НАТО, безопасность, вклад, сотрудничество, замороженный конфликт, членство, уравновешивание. 


\section{Введение}

В терминах геополитического и стратегического значения Южный Кавказ всегда был на переднем крае внешней политики мировых сил. Хотя некогда считалось, что этот регион находится на периферии международной повестки дня, после распада Советского Союза и последовавшего формирования новых независимых государств он стал гораздо более важным как для своих соседей, так и для влиятельных нерегиональных акторов. ${ }^{1}$ Сегодня Южный Кавказ является пестрым геополитическим регионом, занимающим стратегическое положение на пути транспортировки каспийской нефти и каспийского газа. Однако, этот регион сталкивается с вызовами неразрешенных конфликтов и социально-политических и экономических проблем, порожденных крахом Советского Союза. ${ }^{2}$ Затяжные конфликты в регионе давно являются источником напряжения как для Грузии, так и для Азербайджана. Хотя НАТО не принимает прямого участия в разрешении конфликтов на территории стран, не входящих в Альянса, на кризис на Южном Кавказе сильное влияние оказывают отношения между НАТО и Россией.

\section{Южный Кавказ - пространство для противоположных интересов}

После того, как в 2004 году Болгария и Румыния стали членами НАТО, а затем в 2007 и членами Европейского Союза, Южный Кавказ стали считать новым рубежом для НАТО и всей структуры европейской безопасности. ${ }^{3}$ Кроме того, для НАТО и его членов роль Южного Кавказа исключительно важна в плане и евразийской безопасности. Многие европейские политологи рассматривают Южный Кавказ в качестве центра экономических интересов и важного транспортного коридора. ${ }^{4}$ Интерес к этому региону подпитывается и другими факторами. Прежде всего, это его природные ресурсы (Каспийский бассейн) и близость трех больших и амбициозных евразийских государств: России, Турции и Ирана. Регион играет критически важную роль и в качестве транспортного и энергетического коридора. Сегодня Европа сильно зависит от российской нефти и российского природного газа. Однако, ЕС стремится помешать России использовать энергию как инструмент принуждения, и Каспийский бассейн имеет важнейшее значение для этой

1 Sergey Markedonov, "NATO Looks to the Caucasus," The National Interest, May 17, 2012, http://nationalinterest.org/ commentary/nato-looks-the-caucasus-6933.

2 Joshua Bartlett and Nino Samvelidze, "Turkey and the South Caucasus: Prospects and Challenges for Cooperation," http://oval.az/turkey-and-the-south-caucasusprospects-and-challenges-for-cooperation/.

3 Markedonov, "NATO Looks to the Caucasus."

4 Tamaz Papuashvili, "Georgia-NATO: Cooperation Prospects," http://gcssi.org/wp2/ $? p=5139$. 
политики. ${ }^{5}$ Таким образом, коридор Азербайджан-Грузия-Турция является стратегическим связывающим звеном между Европой и Центральной Азией, критически важным для ослабления нынешней мертвой хватки России над энергетическими ресурсами. Этот коридор включает в себя как производство, так и транспортировку углеродов.

Пути трех южно-кавказских республик были разными в смысле их геополитической ориентации - Армения является членом ОДКБ, Азербайджан следует независимой политике в отношении мировых сил, и Грузия, очевидно, демонстрирует про-натовскую позицию. Основными элементами для понимания текущей ситуации в регионе являются отсутствие дипломатических отношений между Арменией и Азербайджаном из-за нагорнокарабахского конфликта, повышенная напористость России в регионе и неприсутствие НАТО. О ситуации в регионе можно сказать, что Южный Кавказ является полем игры между Россией и НАТО.

Тогда как у НАТО ограниченная роль, Россия очень сильно вовлечена в дела этого региона, как показывают прошлые и продолжающиеся конфликты, и оказывает на него существенное влияние уже долгое время. После распада Советского Союза Россия имела намерение доминировать над постсоветскими странами и декларировала эту стратегию в качестве приоритета своей внешней политики. Россия имеет обширное присутствие в этом регионе, в том числе военное - в Армении и в отколовшихся от Грузии субъектов. Независимо от этого, способ, которым общие интересы могут быть трансформированы в совместные возможности, зависит не только от российской политики в отношении Южного Кавказа, но и от того, как развиваются отношения Россия-НАТО. Вот почему интересы национальной безопасности и цели внешней политики этих государств должны быть частью переговорного процесса, независимо от занимаемой в отношении России и НАТО позиции. ${ }^{6}$

Критическим пунктом при формулировании будущих ангажементов НАТО в этом регионе является то, что членство в НАТО не есть обязательное условие. Широкое разнообразие программ НАТО направлено на преобразование целостной региональной картины безопасности - с членством или без него. Программа «Партнерство ради мира» (ПрМ) является бесценным инструментом для строительства политических и военных мостов между

5 Eric S. Thompson, "Turkish Influence in the South Caucasus and Levant: The Consequences for NATO and the EU," (Monterey, California: Naval Postgraduate School, September 2013), 37, http://calhoun.nps.edu/bitstream/handle/10945/37733/ 13Sep_Thompson_Eric.pdf.

6 Maria Raquel Freire, "Security in the South Caucasus: the EU, NATO and Russia," NOREF Policy Brief (Norwegian Peacebuilding Resource Centre, February 2013), accessed June 4, 2017, https://noref.no/Publications/Themes/Emerging-powers/ Security-in-the-South-Caucasus-the-EU-NATO-and-Russia. 
членами НАТО и странами-партнерами. ${ }^{7}$ Она повышает безопасность в регионе и способствует его политическому, социальному и экономическому развитию. Своими видами деятельности ПрМ доказала себя как очень успешный механизм для стимулирования и развития оборонного сотрудничества и военной оперативной совместимости между НАТО и странами Южного Кавказа. Но степень и глубина сотрудничества с Азербайджаном и Грузией отличаются от степени и глубины сотрудничества с Арменией. После 2003 года, когда к власти пришел Михаил Саакашвили, Грузия постоянно заявляла, что она стремится к членству в НАТО, и так продолжалось до августа 2008 года, когда российская армия вторглась на ее территорию. В результате этой инвазии Грузия стала более осмотрительной в своих отношениях с Россией. Прошел длительный период времени с момента этой инвазии, и Грузия не ближе к членству в НАТО, чем она была до августовской войны, хотя все еще имеет сильное присутствие в операциях НАТО и весомые доказательства тому, что соответствует военным и политическим стандартам Альянса. На практике, военными действиями в Грузии Россия продемонстрировала свое продолжающееся присутствие в регионе. Этот сигнал был незамедлительно и точно расшифрован осмотрительным Азербайджаном, который усилил мультивекторный характер своей внешней политики в среде региональных геополитических соперничеств и в 2011 году стал членом Движения неприсоединения (ДНП). ${ }^{8}$ Став членом ДНП, Азербайджан заявил, что на данный момент не стремится к членству в НАТО или ОДКБ. Однако, Республика Азербайджан с ее растущим международным престижем придает большое значение развитию отношений с НАТО. Сегодня международные организации высоко оценивают шаги, предпринятые Азербайджаном для обеспечения региональной и глобальной безопасности и защиты его интересов на реципрокной основе. ${ }^{9}$ Хотя у Азербайджана нет прямого намерения присоединиться к НАТО, Азербайджан считается наиболее надежным партнером НАТО в регионе. Это было заявлено 11 апреля 2014 года помощником генерального секретаря НАТО, Сорином Дукару, на конференции по случаю двадцатилетия создания программы «Партнерство ради мира», который сказал, что «Азербайджан является одним из наиболее важных, активных и давних партнеров НАТО. Мы активно развиваем политический диалог с Баку.» ${ }^{10}$ Являясь надежным партнером, Азербайджан

7 Nika Chitadze, "NATO: One of the Main Guarantees of Peace and Security in South Caucasus," in Perceptions of NATO and the New Strategic Concept, ed. Luis Nuno Rodrigues and Volodymyr Dubovyk (Amsterdam: IOS Press, 2011), 61-73.

8 Cavid Veliyev, "Can Trump Shake Up the South Caucasus?" The National Interest, December 18, 2016, http://nationalinterest.org/feature/can-trump-shake-the-southcaucasus-18774.

9 Dhmədov T. "Azərbaycan-NATO əlaqələri genişlənir," Respublika qəzeti, Bakı, fevral 26, 2012, № 046, s.1.

10 Khayal Iskandarov, "The Road of Integration of Azerbaijan into NATO (1994-2014)," The Caucasus and the World 19 (2015): 89. 
сотрудничает с Альянсом во многих областях, в том числе в борьбе с терроризмом, в региональной безопасности, в содействии международной безопасности и, в частности, в поддержке операций НАТО. В этом плане, Азербайджан стремится к достижению военных стандартов НАТО и к сближению с его военными институциями. Политические приоритеты НАТО и его интересы в сфере безопасности соответствуют национальным интересам Азербайджана, и дальнейшее улучшение многосторонних отношений является главным гарантом мира и безопасности в этом регионе.

Доводы в поддержку продолжения отношений Южный Кавказ - НАТО можно сгруппировать следующим образом:

- Оно повышает уверенность в безопасности региона Южного Кавказа

- Оно обеспечивает безопасность добычи и транспортировки нефти и газа.

- Наиболее важные проблемы региона - так называемые «замороженные конфликты» - могут быть решены мирными средствами

- Вооруженные силы становятся оперативно совместимыми с силами НАТО.

Если сотрудничество Южный Кавказ - НАТО действует как гарант региональной безопасности, то тогда следует через эту призму проанализировать характер всех возможных угроз. Итак, какие угрозы существуют в этом регионе? В теперешнем общественно-политическом климате очевидные угрозы наиболее вероятно исходят из тех стран, чьим интересам противоречат экономические и политические интересы НАТО. Поэтому, чтобы понять природу этих угроз, необходимо определить области противоречащих интересов. Прежде всего, это каспийские месторождения нефти и газа. В этой области интересы НАТО серьезно сталкиваются с интересами России, и Россия десятилетиями использует «замороженные конфликты» для того, чтобы держать в страхе регион и угрожать его нефтяной и газовой инфраструктуре. Действительно, эти конфликты, перемежаемые многочисленными асимметричными угрозами в регионе, являют собой проблемную среду для восточного фронта НАТО. Россия ведет двойную игру на Южном Кавказе, одновременно обеспечивая стабильность и нарушая стабильность этого региона. С одной стороны, есть Россия-посредник при конфликтах, который договаривается о прекращениях огня и стремится к разрешению конфликтов на Южном Кавказе в рамках своего мандата сопредседателя Минской группы Организации по безопасности и сотрудничеству в Европе. С другой стороны, есть Россия-провокатор. Спровоцировав свою собственную войну с Грузией в 2008 году, Россия признала два отколовшихся субъекта Грузии независимыми государствами и все еще имеет военное присутствие на их 
территории. ${ }^{11}$ Россия также поддерживает как в экономическом, так и в военном плане Армению, которая оккупирует 20 процентов территории Азербайджана.

Сегодня Россия обвиняет НАТО в дестабилизации Кавказского региона совместными учениями в Грузии, но сама она развернула постоянные военные базы в Армении, а также в сепаратистских регионах Южная Осетия и Абхазия. Воодушевленная российской поддержкой, Армения все еще удерживает Нагорный Карабах под оккупацией. Однако, у Запада нет эффективных политических или военных средств для балансирования российского военного присутствия в Армении. Несбалансированное и подавляющее российское военное присутствие Армении создает серьезную и прямую угрозу для западной нефтяной и газовой инфраструктуры и трубопроводов. ${ }^{12}$ Все-таки Россия использует свое положение посредника для продвижения своих собственных интересов, а не для действительного разрешения конфликта. Пока три южно-кавказских республики остаются разделенными, Россия будет над ними властвовать. Не секрет, что конфликты на Южном Кавказе используются Россией для оказания политического давления на Грузию, Армению и Азербайджан. В двух словах, Россия применяет политику «разделяй и властвуй» посредством затянувшихся конфликтов. Очевидно, нынешнее статус-кво выгодно для российских интересов, оно способствует сохранению ее сферы экономического и военного влияния и мешает какому-либо южно-кавказскому государству поглядывать в сторону HATO.

\section{Raison d'être [причина] НАТО для дальнейшего участия в делах региона}

НАТО придает большое значение Кавказскому региону и обеспокоено эскалацией напряжения в нем. Все три страны участвуют в европейском Восточном партнерстве, а безопасность в соседних государствах является одним из главных интересов НАТО. Однако, по ряду причин НАТО прилагало мало усилий для активного содействия безопасности на Южном Кавказе. Действительно, у НАТО не хватает согласованности политики в отношении Южного Кавказа. Прежде всего, Альянс старается не дразнить Россию. Российско-грузинская война и украинский кризис сделали Запад менее склонным к вмешательству и поэтому расширение НАТО в регионе Южного Кавказа вряд ли в обозримом будущем войдет в повестку дня Альянса. Однако, мы можем предположить, что НАТО сможет служить противовесом России и способствовать целостной интеграции региона в институции НАТО через

11 Tatia Dolidze, "Russian and Western engagement in the South Caucasus conflicts: Building sustainable stability in the region?" December 2, 2015.

12 Mahir Khalifazadeh, "The South Caucasus: Obama's Russia 'Reset' and Putin's Doctrine," CESRAN International, July 27, 2014, http://cesran.org/the-south-caucasusobamas-russia-reset-and-putins-doctrine.html. 
программы партнерства. Говоря о перспективах сотрудничества между странами Южного Кавказ и НАТО, следует держать в уме множество разнообразных региональных факторов. На саммите в Бухаресте в 2008 году российский президент, Владимир Путин, заявил, что он воспринимает существование могущественного военного альянса неподалеку от границ России прямой угрозой российской национальной безопасности и российским национальным интересам. ${ }^{13}$ Кроме того, в отношении Грузии и Украины он отметил:

Он [грузинский конфликт] является старым, многолетним, продолжающимся более сотни лет этническим конфликтом между грузинами, ... абхазцами, ... осетинами. Чтобы решить эти проблемы, им не нужно входить в НАТО, у них должно быть терпение, они должны устанавливать диалог с малыми этническими группами. И мы пытаемся им помочь. ... Но на Украине треть населения является этническими русскими. Из сорока пяти миллионов, согласно переписи, есть районы, в которых проживает только русское население, к примеру, в Крыму $90 \%$ - это русские. ... Хорошо, семнадцать миллионов русских сейчас проживает на Украине. Кто может утверждать, что у нас нет никаких интересов там? ${ }^{14}$

В результате этого, хотя президент Буш решительно поддерживал предоставление Украине и Грузии ПДч (Плана действий по членству), Объединенное Королевство, Франция и Германия воспротивились этой идее. Британская оценка была, что хотя они полностью поддерживают Украину и Грузию, вопрос о том, когда они присоединятся, должен оставаться в ожидании взвешенного ответа. Германия и Франция заявили, что они считают, что поскольку ни Украина, ни Грузия не являются достаточно стабильными, чтобы войти в программу, план по членству был бы ненужным оскорблением России. ${ }^{15}$ Германия все еще относится к этому скептически, опасаясь, что принятие Грузии втянет Атлантический Альянс в конфронтацию с Россией. Таким образом, хотя и временно, Россия смогла на обозримое будущее помешать какому-либо расширению НАТО в сторону постсоветских границ 2008 года, поскольку российское военное вмешательство остается весьма реальной угрозой для постсоветских стран, соседствующих с ней.

НАТО может быть sine qua non [обязательным условием] безопасности на Южном Кавказе. Но это не означает, что страны Южного Кавказа должны

13 Nəzakət Məmmədova, "NATO: Şimali Atlantikadan Şərqi Avropaya doğru," Xalq qəzeti 81, aprel 18, 2008, s.5.

14 "Text of Putin's speech at NATO Summit," UNIAN (Bucharest, April 2, 2008), http://www.unian.info/world/111033-text-of-putins-speech-at-nato-summitbucharest-april-2-2008.html.

15 Steven Erlanger and Steven Lee Myers, "NATO Allies Oppose Bush on Georgia and Ukraine," New York Times, April 3, 2008, http://www.nytimes.com/2008/04/03/ world/europe/03nato.html. 
стать полноправными членами. Наиболее обещающим и, возможно, единственным средством устранения «дефицита безопасности» на Южном Кавказе является постепенное расширение программ НАТО в этом регионе. Страны региона, в том числе Армения, постепенно осознают, что их отношения с НАТО на деле состоят в том, как выбрать, развивать и интегрировать программы НАТО, которые постепенно со временем изменят всю картину безопасности в регионе. ${ }^{16}$

В то время как появляются новые глобальные риски, сфера безопасности расширяется в сторону необычных вызовов безопасности, которые требуют от традиционных институций быстрой адаптации, расширения их ответственностей, задач, а иногда и средств, находящихся в их распоряжении. Среди этих проблем одним из основных является энергетическая безопасность. Сегодня энергетика более политизирована, становится эффективным оружием для принуждения и для создания неразрешимых расхождений между собственниками и потребителями энергии. Поскольку НАТО признает, что энергетическая безопасность быстро становится важным вопросом для европейской безопасности и будет одним из наиболее важных вызовов для Союзников, значение Южного Кавказа существенно возрастает. В результате политических трений в энергетических отношения между ЕС и Россией весной 2006 года, а позже - между Россией и Украиной в январе 2009 года, государства-члены призвали к подключению НАТО к вопросам энергетической безопасности. ${ }^{17}$ Однако, отсутствие консенсуса не позволило НАТО принять более широкое участие в разрешении проблем энергетической безопасности. Ключевую роль могут играть, и более подходящими для разрешения главных проблем инвестирования и эффективности могут быть другие институции, например ЕС. Тем не менее, НАТО может иметь положительный вклад в энергетическую безопасность своих членов, и конечно, в глобальную энергетическую безопасность. Более того, отсутствие ясности относительно роли НАТО и причин, по которым оно должно играть эту роль, особенно в плане его географической роли, может усложнить отношения НАТО со странами-партнерами и другими третьими сторонами (в данном случае с Россией). Значение гарантирования энергетической безопасности еще раз было подчеркнуто и одобрено Союзниками в ноябре 2010 года. 13-й пункт стратегической концепции НАТО идентифицирует увеличенную зависимость государств от «жизненно важных коммуникационных, транспортных и транзитных маршрутов, от которых зависят энергетическая безопасность, международная торговля и процветание». ${ }^{18}$

16 Chitadze, "NATO: One of the Main Guarantees."

17 Chitadze, "NATO: One of the Main Guarantees."

18 Речь при открытии посла Румынии в Азербайджане, Даниела Кристиана Чиобану, Международный семинар по обеспечению энергетической безопасности в Каспийском бассейне и роли НАТО в защите критической энергетической инфраструктуры, Баку, 22 ноября 2012. 
Основными препятствиями для ключевой роли НАТО для энергетической безопасности в Кавказском регионе являются ${ }^{19}$ :

- Отсутствие средств и инструментов в расположение НАТО, что мешает попыткам реализовать намерения, выраженные в Стратегической концепции НАТО;

- Нежелание России участвовать в общих с НАТО мероприятиях. Любое действие, которое предпринял бы Альянс, особенно с участием военных, может вызвать российскую реакцию, направленную на нейтрализацию евроатлантического присутствия в таком жизненно важном для ее национальных интересов регионе;

- Разногласия в самом НАТО по поводу более широкого участия в обеспечении энергетической безопасности;

- Слабое сотрудничество по энергетической безопасности со странами-партнерами из Каспийского региона.

Однако, постоянно возрастающая необходимость в диверсификации источников энергии и сотрудничества по проблемам транзита энергии, возможно, заставили Запад придать гораздо большее значение региону Южного Кавказа (коридор Азербайджан-Грузия-Турция) в качестве надежного транзитного маршрута, обходящего российскую и иранскую территорию. Нефтепровод Баку-Тбилиси-Джейхан и газопровод Баку-Тбилиси-Эрзерум представляют собой шаг вперед в этом сотрудничестве, особенно в сочетании с предстоящими проектами ТАНАП и ТАП. ${ }^{20}$ Дальнейшее развитие Каспийского региона будет иметь существенное влияние на стратегическое равновесие в мире в связи с предоставлением ключевого доступа к ресурсам Центральной Азии. Роль Южного Кавказа в обеспечении энергетической безопасности Европы также приветствуется США. Белый дом решительно поддерживает инициированный Азербайджаном проект Южного газового коридора, который будет переносить газ из месторождения «ШахДениз II» к европейским потребителям. Джон Кэрри сказал, что «этот проект был очень важным шагом в отношение долгосрочных европейских интересов и, честно говоря, попыткой диверсифицировать источники энергии, что очень важно». ${ }^{21}$ В результате этой политики существующие инструменты и новые инициативы, направленные на диверсификацию источников энергии, повысят энергетическую безопасность Европы и безопасность Альянса в целом. Здесь роль НАТО состоит в том, чтобы добавить стоимости

19 Aurora Ganz, "Energy Security Issues: Is NATO Becoming a (Pivotal) Actor?" SciencesPo, Centre de Recherches Internationales, September 2014, по состоянию на 4 июня 2017, http://www.sciencespo.fr/ceri/fr/content/dossiersduceri/energy-securityissues-nato-becoming-pivotal-actor.

20 Bartlett and Samvelidze, "Turkey and the South Caucasus."

21 Aynur Karimova, "Kerry appraises Azerbaijan's role in international security system," AZERNEWS, March 31, 2016, по состоянию на 18 января 2018, www.azernews.az/ nation/94480.html. 
политике по энергетической безопасности ЕС и вымостить дорогу к энергетической безопасности.

Учитывая стратегический характер региона, НАТО следует внимательно следить за развитием событий на Южном Кавказе в политической и экономической сфере. Кроме того, Россия показала, что она использует замороженные конфликты и энергетику в качестве инструментов для оттеснения НАТО от своих границ и для ослабления его единства. Если мы рассмотрим все не натовские страны на европейской периферии России, мы увидим, что только Финляндия, Швеция и Беларусь не имеют конфликтов на своей территории. Первые две являются нейтральными государствами, а последнее - член ОДКБ. Из всего этого мы можем сделать вывод, что членство в НАТО для стран, стремящихся к нему, стало иллюзорным даже в оптимистическом сценарии обозримого будущего. Однако, это не означает, что НАТО следует стоять в сторонке от проблемы конфликтов, поскольку их затяжное существование является существенной угрозой для целостной европейской безопасности. ${ }^{22}$

\section{Заключение}

Россия не остановится ни перед чем для того, чтобы осуществлять свое влияние на свое «ближнее зарубежье» и заново утвердить себя в качестве доминирующей силы на постсоветском пространстве. Южный Кавказ, с его близостью к России, занимает первое место в этом «ближнем зарубежье». Единственный способ для стран Южного Кавказа (Грузии и Азербайджана) искоренения проблем, связанных с замороженными конфликтами, это нахождение правильного баланса между НАТО и Россией, поскольку Россия, по-видимому, не желает отказываться от своих политических амбиций в этом регионе. Сотрудничество с НАТО имеет важнейшее значение для всех этих трех стран. Вот почему, поскольку Армения является членом ОДКБ, Грузия и Азербайджан должны следовать примеру Швеции и Финляндии для расширения дальнейшего сотрудничества с НАТО. Альянс мог бы расширить военное сотрудничество с Азербайджаном для способствования миру и стабильности на Южном Кавказом путем развития активных партнерских отношений без действительного членства в НАТО. Это так, поскольку любой шаг, который предпримет какое-либо государство Южного Кавказа к членству в НАТО, может вызвать негативную реакцию России. Поэтому, как и во время российско-грузинской войны в 2008 году, НАТО с неохотой будет реагировать на любое действие России. Таким образом, близкое практическое, а не политическое, сотрудничество с НАТО улучшит оборонные способности Азербайджана и Грузии, подобно тому, как это случилось с Швецией и Финляндией. Такая стратегия могла бы ослабить суще-

22 Xavier Follebouckt, "The South Caucasus's Still Frozen Conflicts," Atlantic Voices 6, no. 7 (July 2016), http://atahq.org/2016/07/atlantic-voices-south-caucasus/. 
ствующее напряжение между Россией и Западом и частично компенсировать военное присутствие России в Армении и в отколовшихся от Грузии регионов.

Европа уязвима в плане энергетического принуждения, и тандем Азербайджан-Грузия-Турция дает лучшую возможность для противодействия такому вымогательству. Обеспечение безопасности в регионе в интересах стран-импортеров, транзитных стран и стран-экспортеров, которым нужны гарантии безопасности их производственной и трубопроводной инфраструктуры. Вот почему регион Южного Кавказа следует рассматривать как буферную зону между НАТО и Россией, пока не будут улажены «замороженные конфликты» и реализованы все энергетические проекты. Но односторонний подход может только усугубить существующие на территориях Грузии и Азербайджана кризисы.

\section{Об авторах}

Профессор Эльман Насиров, доктор политических наук и директор Института политических исследований Академии публичной администрации при Президенте Азербайджана. Он также является членом парламента Республики Азербайджан.

Хаял Искандаров является начальником учебного отдела Военной академии Вооруженных сил Республики Азербайджан. У него степень магистра военных наук и в настоящее время он аспирант на соискание степени кандидата наук в области военных наук и национальной безопасности.

E-mail: xayal1333@gmail.com.

Сади Садиев, кандидат филологических наук, доцент в Военной академии Вооруженных сил Республики Азербайджан.

E-mail: sanansadiyev@yahoo.co.uk. 